05

\title{
Спинодальный распад вольфрамсодержащих фаз в функциональных покрытиях, получаемых в высокоэнергетических процессах имплантирования
}

\author{
(C) C.B. Давыдов, ${ }^{1}$ E.B. Петров ${ }^{2}$ \\ ${ }^{1}$ Брянский государственный технический университет, \\ 241035 Брянск, Россия \\ ${ }^{2}$ Институт структурной макрокинетики и проблем материаловедения РАН, \\ 142432 Черноголовка, Россия \\ e-mail: davidov69@tu-bryansk.ru
}

(Поступило в Редакцию 16 ноября 2016 г.)

Исследованы структурные и фазовые превращения в вольфрамсодержащих функциональных покрытиях углеродистых сталей, получаемых в высокоэнергетических процессах имплантирования микропорошков карбида вольфрама методом комплексной импульсной электромеханической обработки и микропорошков вольфрама в технологии направленной энергией взрыва на основе эффекта сверхглубокого проникания твердых частиц или эффекта Ушеренко. Показано, что при термосиловом воздействии в зоне деформации протекает интенсивная аустенизация стали с растворением порошка карбида вольфрама, карбидизацией порошка вольфрама и последующим образованием композиционных градиентных структур в результате распада пересыщенного вольфрамом переохлажденного аустенита как по диффузионному механизму, так и по механизму спинодального распада. Показано, что отдельные зоны вольфрамсодержащих фаз сплава находятся в жидкофазном состоянии и также претерпевают спинодальный распад с образованием высокодисперсных карбидных фаз глобулярной морфологии.

DOI: 10.21883/JTF.2017.08.44726.2101

\section{Введение}

В настоящее время интенсивно развиваются синерготехнологии [1], которые включают в себя не только аддитивные технологии по классификации стандарта ASTM [2], но и традиционные упрочняющие технологии, например индукционного нагрева, плазменного напыления, поверхностного модифицирования, ионной имплантации и др. [1]. Особенностью данных технологий является применение высокоэнергетических и концентрированных источников энергии.

Основной задачей синерготехнологий является обеспечение самоорганизации поверхностных явлений при последовательном формировании структур функциональных поверхностных слоев различных материалов или градиентных структур и управление свойствами этих структур при разнообразном физическом высокотемпературном и силовом воздействиях. При этом ключевым элементом самоорганизации поверхностных явлений является устойчивое и стабильное формирование слоя определенной толщины с заданной структурой или фазовым составом, обеспечивающим требуемый комплекс служебных свойств. Одним из ключевых вопросов является вопрос о процессах структурообразования в формирующемся слое.

В настоящей работе исследовали фазовый состав и процессы формирования градиентных структур функциональных покрытий, получаемых в высокоэнергетических процессах имплантирования: комбинированной импульсной электромеханической обработке [3-5] и в технологии использования воздействия потока тугоплавких частиц, разогнанных направленной энергией взрыва, на основе эффекта сверхглубокого проникания твердых частиц $[6,7]$.

\section{Результаты исследований}

Комбинированная импульсная электромеханическая обработка включает в себя два этапа. На первом этапе (режим „высокотемпературная пластическая деформация““) происходит имплантирование под определенной нагрузкой порошка карбида вольфрама размером частиц до $9 \mu \mathrm{m}$ из специальной графитной обмазки, наносимой на поверхность детали из углеродистой стали 45, в процессе перекатывания ролика из стали 95X18. Частицы карбида вольфрама, перемешиваясь с пластически деформируемым металлом, внедряются в процессе деформации в формируемый функциональный поверхностный слой.

На втором этапе (режим „высокотемпературное термическое упрочнение“) применяется ролик из псевдосплава „карбид вольфрама-медь“ для обеспечения сочетания высоких температур и давлений в зоне контакта, под воздействием которых в момент электрического импульса происходит аустенизация поверхностного слоя стали в зоне контакта ролика и обрабатываемой поверхности. При этом углерод из обмазки в твердофазном процессе высокотемпературного насыщения диффундирует в поверхностные слои детали, повышая содержание 


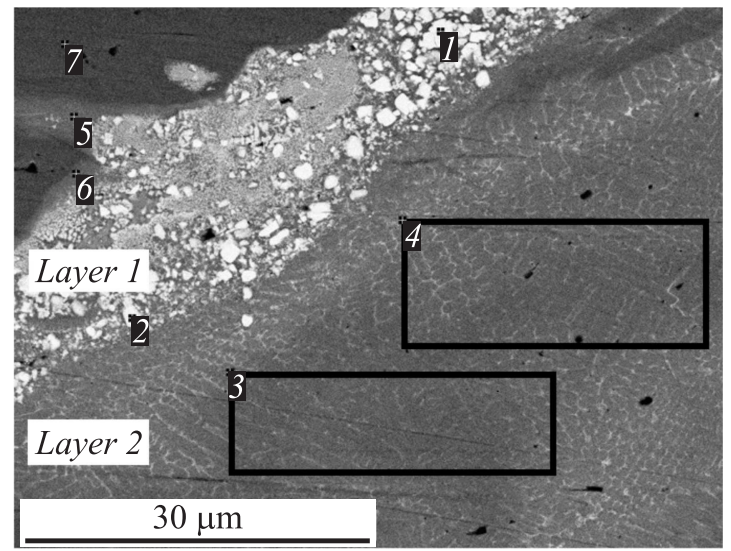

Рис. 1. Микроструктура слоя 1 (частицы карбида вольфрама) и слоя 2 (сетка карбида вольфрама по границам аустенитных зерен).

Таблица 1. Энергодисперсионный анализ слоев, wt.\%

\begin{tabular}{c|c|c|c|c|c|c|c}
\hline Спектр & 1 & 2 & 3 & 4 & 5 & 6 & 7 \\
\hline $\mathrm{C}$ & 16.8 & 7.6 & 3.3 & 3.6 & 15.1 & 11.8 & 11.3 \\
$\mathrm{Al}$ & - & - & - & - & 0.6 & 0.7 & 0.6 \\
$\mathrm{Fe}$ & 4.0 & 6.4 & 84.2 & 83.6 & 71.5 & 76.9 & 88.1 \\
$\mathrm{Cr}$ & - & 14.7 & - & - & - & - & - \\
$\mathrm{Cu}$ & - & - & 2.9 & 2.7 & 4.0 & 2.1 & - \\
$\mathrm{W}$ & 79.2 & 71.3 & 9.6 & 10.1 & 8.8 & 8.5 & -
\end{tabular}

углерода в аустените. Карбиды вольфрама частично растворяются в аустените до предела его насыщения вольфрамом.

В результате обработки на функциональной поверхности формируется трехслойная градиентная структура. Она состоит из первого верхнего, упрочненного слоя толщиной $180-220 \mu \mathrm{m}$, насыщенного исходными частицами карбида вольфрама, второго нижнего слоя толщиной 200-250 $\mu \mathrm{m}$, состоящего из ячеистой структуры аустенитных зерен, границы которых армированы карбидовольфрамовой сеткой, и третьего слоя с толщиной 20-40 $\mu \mathrm{m}$ также насыщенного карбидами вольфрама.

Микроструктурные исследования проводились на автоэмиссионном сканирующем электронном микроскопе. На рис. 1 показана микроструктура слоев 1 и 2, в табл. 1 представлен результат энергодисперсионного анализа. Слой 1 представляет собой смесь имплантированных частиц карбида вольфрама и матричной основы стали 45. Следовательно, в процессе имплантирования на этапе „высокотемпературное пластическое деформирование“ происходит интенсивное пластическое перемешивание частиц карбида вольфрама в объеме стали в твердофазном состоянии и их частичное растворение в аустените. В табл. 1 присутствуют элементы $\mathrm{Cr}$ и $\mathrm{Cu}$. Их появление связано с использованием различных роликов. В режиме „высокотемпературное пластическое деформирование“ использовался ролик из стали $95 \mathrm{X} 18$ и хром из ролика частично диффундировал в карбид вольфрама (рис. 1, точка 2). В режиме „высокотемпературное термическое упрочнение“ использовался ролик из псевдосплава „карбид вольфрама-медь“ и медь, находящаяся в псевдосплаве в несвязанном состоянии с ролика перешла в твердый раствор аустенита (рис. 1, точки 3-7).

Энергодисперсионный анализ и характер структурообразования показывают, что в режиме „высокотемпературное термическое упрочнение“ в момент прохождения силового электрического импульса в сочетании с максимальной нагрузкой деформирования на ролик в слое 2 выделяется максимальное количество энергии, которое переводит систему в метастабильное состояние с последующим образованием ячеистой структуры (рис. 2).

Для упрочнения функциональных плоских или фасонных поверхностей с большой площадью, например поверхности штампов, традиционные технологии упрочнения, как правило, либо не применимы, либо слишком удорожают инструмент.

Для разработки принципиально новой технологии упрочнения сложных фасонных поверхностей большой протяженности использовали эффект сверхглубокого проникания частиц, открытый С.М. Ушеренко [6,7]. Данный эффект заключается в том, что твердые частицы, разогнанные энергией взрыва, при скоростях $2.0-3.0 \mathrm{~km} / \mathrm{s}$ проникают в металлическую преграду на аномально большую глубину, превышающую размер частицы в десятки и сотни раз. В работах $[6,7]$ достаточно подробно исследованы различные физические стороны эффекта, но практически нет исследований процессов структурообразования в зоне воздействия твердых частиц с металлической матрицей и влияния имплантированных частиц на механические свойства упрочненного материала.

Для улучшения эффективности и оптимизации технологического использования в работах $[8,9]$ исследовали закономерности воздействия потока частиц порошка вольфрама для упрочняющей обработки функциональной поверхности стальных изделий. Для исследования влияния эффекта сверхглубокого проникания частиц на фазовые превращения и твердость поверхностных функ-

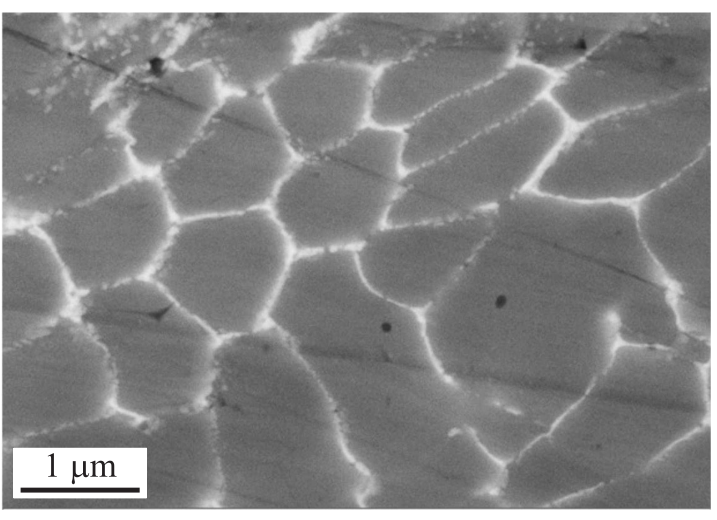

Рис. 2. Ячеистая структура переохлажденного аустенита в слое 2 . 


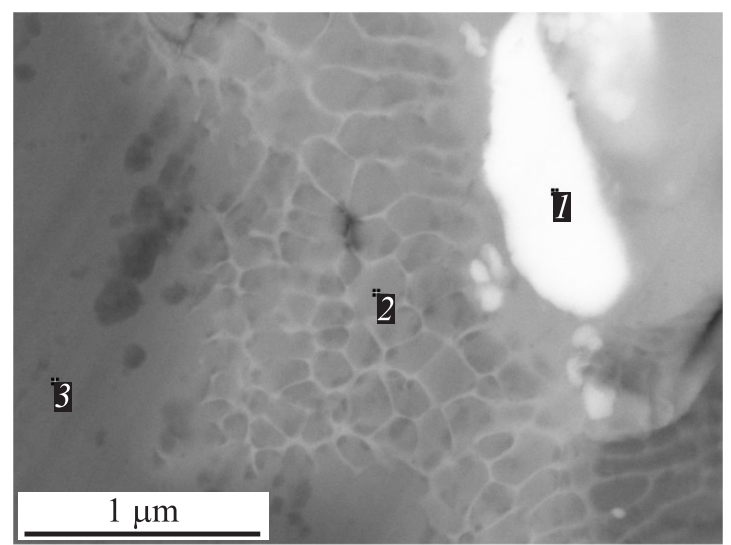

Рис. 3. Ячеистая структура переохлажденного аустенита с сеткой карбида вольфрама и с включениями вольфрама в структуре стали, упрочняемой потоком частиц вольфрама, разогнанных энергией взрыва.

Таблица 2. Энергодисперсионный анализ поверхности, обработанной потоком частиц вольфрама, wt.\%

\begin{tabular}{c|c|c|c}
\hline Спектр & 1 & 2 & 3 \\
\hline $\mathrm{C}$ & 24.17 & 26.79 & 25.01 \\
$\mathrm{Fe}$ & 12.95 & 59.90 & 74.99 \\
$\mathrm{~W}$ & 62.89 & 13.30 & -
\end{tabular}

циональных слоев инструментальной стали У8 разработана установка для взрыва с направляющим каналом [8]. При детонации ударная волна и продукты взрыва разгоняли порошок вольфрама размером частиц $10-16 \mu \mathrm{m}$ и вместе с ним воздействовали на исследуемый цилиндрический образец диаметром $24 \mathrm{~mm}$ и высотой $40 \mathrm{~mm}$. С помощью сканирующего электронного микроскопа были обнаружены частицы вольфрама на глубине $\sim 13 \mathrm{~mm}$ от поверхности соударения, что превышает исходный размер частицы вольфрама $(14 \mu \mathrm{m})$ в 930 раз. При соударении потока частиц порошка вольфрама с поверхностью расчетное давление составило $P=62 \mathrm{GP}$.

В структуре стали, как и в экспериментах по комбинированному электромеханическому упрочнению, также обнаружена ячеистая структура аустенита с сеткой карбида вольфрама и с включениями частиц вольфрама (рис. 3). В табл. 2 представлен результат энергодисперсионного анализа.

Оценочный теоретический расчет температуры нагрева частиц вольфрама показал, что верхний предел температуры ударного сжатия частиц вольфрама с преградой составляет $t_{\max }=972^{\circ} \mathrm{C}$. Следовательно, при ударном воздействии частиц порошка вольфрама со сталью У8 температура превышает температуру перитектоидной реакции в системе $\mathrm{Fe}-\mathrm{W}$, образуется высокоуглеродистый аустенит, который при охлаждении стабилизируется растворенным вольфрамом, и формируется сетчатая ячеистая структура (рис. 3). Данная структура полно- стью аналогичная структуре на рис. 2 , но ячеистая структура аустенита на рис. 3 в значительной степени более дисперсная (примерно в 5 раз меньше) в сравнении с аналогичной структурой на рис. 2.

Таким образом, и при импульсном имплантировании порошка карбида вольфрама в сталь 45 методом комбинированной электомеханической обработки, и при обработке поверхности образцов из стали У8 потоком частиц порошка вольфрама, разогнанных энергией взрыва, температура в активной зоне превышает уровень температуры перитектоидной реакции в $1060^{\circ} \mathrm{C}$ в системе $\mathrm{Fe}-\mathrm{W}$. Максимальной границей нагрева стали при термосиловом воздействии при имплантировании можно считать границу до $1300^{\circ} \mathrm{C}$. Как следствие, в структуре стали образуется ячеистый переохлажденный аустенит с сеткой карбида вольфрама по границам зерен, что идентично структуре литой быстрорежущей стали со сложной карбидной эвтектикой, напоминающей ледебурит и располагающейся также по границам зерен аустенита.

В отдельных областях структуры при переходе от слоя 1 к слою 2 (рис. 1) обнаружены необычные структурные образования вблизи скоплений крупных частичек порошка карбида вольфрама (рис. 4). Данные структуры

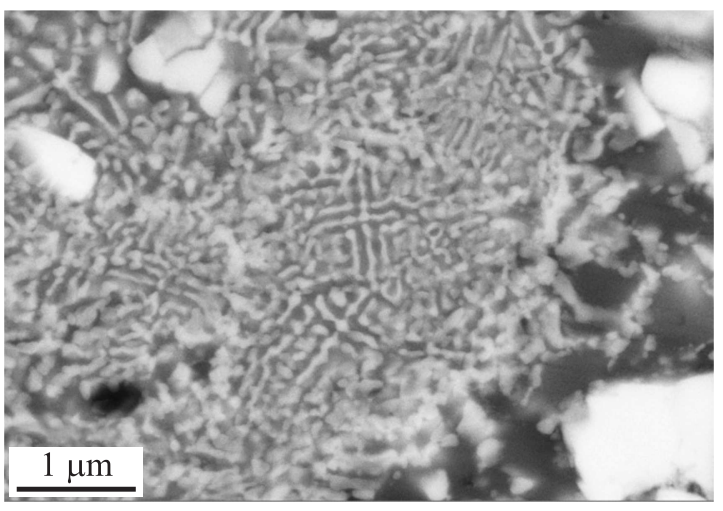

Рис. 4. Структура эвтектического типа и глобулярные кристаллы карбида вольфрама в переходных зонах упрочненного слоя в функциональном слое стали 45.

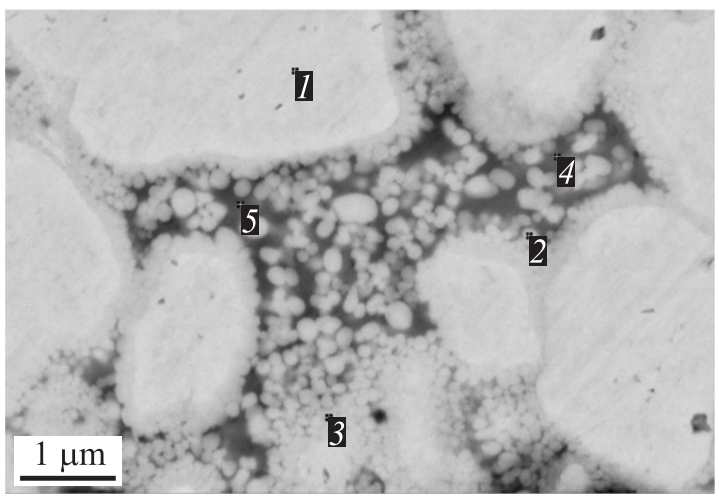

Рис. 5. Кристаллы глобулярной формы по границам частиц вольфрама в стали У8. 
имеют ярко выраженное эвтектическое строение, однако состоят из нитевидных кристаллов карбида вольфрама, чередующихся с изолированными глобулярными частичками карбида вольфрама высокой степени дисперсности. Причем сами нити состоят из коагулировавших мельчайших глобулей карбида вольфрама.

Аналогичные глобулярные структуры, только более ярко выраженные, обнаружены в стали У8, упрочненной потоком частиц вольфрама, разогнанных энергией взрыва (рис. 5). Особенностью данной структуры является своеобразная карбидная „бахрома“ из глобулярных, близких к шаровидной форме дисперсных частиц карбида вольфрама по фазовой поверхности частиц вольфрама (рис. 5, точка 1). Причем более мелкие частицы карбида вольфрама покрыты карбидной „бахромой“ в несколько слоев (рис. 5, точки 2 и 3). Необычно и выделение значительно более крупных карбидных глобулей в переохлажденном аустените (рис. 5, точки 4 и 5).

Формирование высокодисперсных нитевидных карбидных (рис. 4) и глобулярных карбидных структур в виде „бахромы“ (рис. 5) не может быть объяснено c позиций выделения избыточного вольфрама из пересыщенного аустенита по диффузионному механизму распада, как в случае образования структуры ячеистого типа (рис. 2 и 3 ).

\section{Обсуждение результатов}

Оценка характера процессов структурообразования на рис. 1 и 2 показывает, что в соответствии с диаграммой $\mathrm{Fe}-\mathrm{W}$, температура в функциональных слоях с ячеистой структурой аустенита превышает температуру $1060^{\circ} \mathrm{C}$, соответствующую перитектоидной реакции. В этих температурных условиях протекает полиморфное превращение железа с образованием аустенита и растворением карбида вольфрама в аустените.

Например, в аустените стали Р6М5 при оптимальной температуре нагрева под закалку $\left(1200-1230^{\circ} \mathrm{C}\right)$ растворено около 8\% вольфрама. В стали Р18 в аустените растворяется также около 8\% вольфрама, но при температурах $1270-1290^{\circ} \mathrm{C}$. Следовательно, максимальной границей нагрева стали при термосиловом воздействии при импульсном имплантировании можно считать границу до $1300^{\circ} \mathrm{C}$.

При охлаждении раствор аустенита пересыщается вольфрамом и стабилизируется. При дальнейшем охлаждении формируется структура стабилизированного переохлажденного аустенита, а избыток вольфрама выделяется в виде сетки карбида вольфрама по границам аустенитных зерен, слаболегированных вольфрамом. В данном случае полученная структура идентична структуре литой быстрорежущей стали, соответствующей сложной карбидной эвтектике, напоминающая ледебурит и располагающаяся по границам зерен.

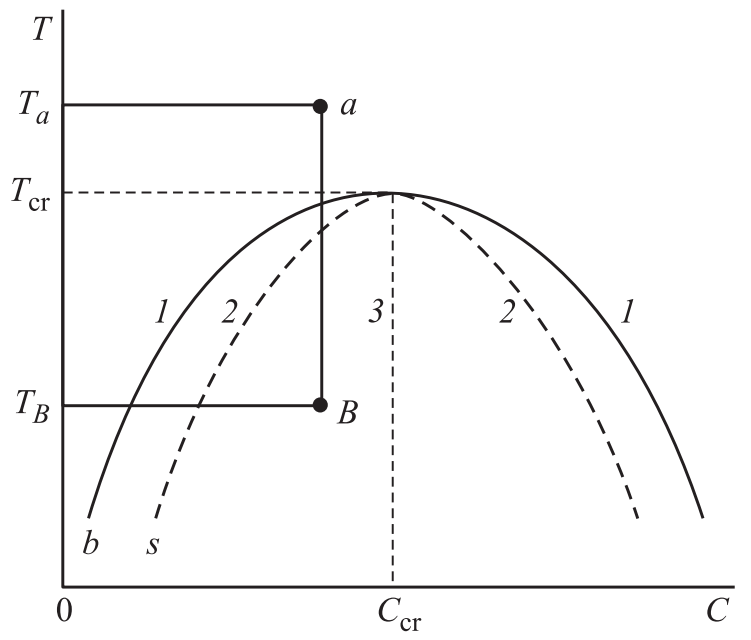

Рис. 6. Фазовая диаграмма твердого раствора с ограниченной растворимостью одного из компонентов в твердом состоянии: 1 - область устойчивых однородных состояний, 2 - область метастабильной устойчивости, 3 - область неустойчивых (лабильных) состояний.

Формирование локальных структур, показанных на рис. 4 и 5, можно объяснить процессом спинодального распада $[10,11]$.

Рассмотрим в общем виде поведение двухкомпонентной системы с ограниченной растворимостью одного из компонентов в твердом состоянии, как и в случае твердого раствора вольфрама в железе. Типичная диаграмма такой системы в координатах $T-C$ с верхней критической точкой $\left(T_{\mathrm{cr}}\right)$ показана на рис. 6 .

Такая система может находиться в трех качественно различных состояниях, области существования которых на фазовой диаграмме (рис. 6) разграничены бинодалью $b$ (в любой точке бинодали химические потенциалы двух равновесных фаз равны, $\left.\mu_{i}=\mu_{j}\right)$ и спинодалью $s$ (в любой точке спинодали коэффициент взаимной диффузии компонентов раствора равен нулю, $\left.D_{0}=0\right)$. Во внешней к бинодали $b$ области 1 устойчиво фазовое состояние с однородным пространственным распределением концентрации $C$, которому соответствует жидкая фаза или твердый раствор. Между бинодалью $b$ и спинодалью $s$ находится область 2 метастабильных состояний, в которой диффузия обеспечивает движение системы к одному из термодинамически выгодных однородных фазовых состояний.

В случае отсутствия активного химического взаимодействия между атомами диффузионный поток пропорционален градиенту концентрации и направлен в сторону выравнивания концентраций в системе, и уравнение диффузии имеет вид

$$
\frac{\partial c}{\partial t}=\frac{\partial}{\partial x}\left(D_{0} \frac{\partial c}{\partial x}\right)
$$

где $D_{0}-$ коэффициент диффузии, не зависящий от концентрации. 
Процесс кристаллизации системы в области 2 идет по классическому диффузионному механизму гомогенного или гетерогенного зародышеобразования и завершается формированием структурно-однородного фазового состояния, в котором выполняется равенство химических потенциалов двух равновесных фаз:

$$
\mu_{1}=\mu_{2}
$$

Под спинодалью $s$ находится область 3 крайне абсолютно неустойчивых или лабильных однородных состояний. В лабильной области 3 коэффициент диффузии отрицателен или наблюдается явление „восходящей“ диффузии, при которой любая пространственная флуктуация структурируется и основное состояние оказывается пространственно-неоднородным, но характеризуется при этом определенной упорядоченностью. Реализация такого спонтанного нарастания малых возмущений концентрации по всему объему системы при переходе системы через спинодаль $s$ и называется неравновесным фазовым переходом или спинодальным распадом раствора.

При спинодальном распаде в общем случае диффузионный поток определяется не градиентом концентрации, а градиентом химического потенциала. В этом случае диффузионные процессы ведут к состоянию, характеризуемому условием постоянства в данном объеме химического потенциала $\mu=$ const.

В этом случае уравнение диффузии имеет вид

$$
\frac{\partial c}{\partial t}=b \frac{\partial}{\partial x}\left(C \frac{\partial \mu}{\partial x}\right)
$$

где $b-$ подвижность, принимаемая постоянной, $\mu-$ химический потенциал диффундирующего элемента.

Подставляя в уравнение (3) известное выражение

$$
\mu=\mu_{0}+R T \ln \gamma c,
$$

где $\gamma$ - коэффициент активности компонента в растворе, получаем уравнение диффузии при спинодальном распаде аналогичное уравнению (1) в виде

$$
\frac{\partial c}{\partial t}=\frac{\partial}{\partial x}\left(D_{(C)} \frac{\partial c}{\partial x}\right),
$$

где

$$
D_{(C)}=D_{0}\left(1+\frac{\partial \ln \gamma}{\partial \ln C}\right) .
$$

Анализ уравнения (5) приводит к понятию „восходящей“ диффузии.

Если $D_{(C)}<0$, т. е. если

$$
\left(1+\frac{\partial \ln \gamma}{\partial \ln C}\right)<0,
$$

то диффузия ведет не к выравниванию концентраций, а к усугублению концентрационных неоднородностей по всему объему системы, находящейся в спинодальной области.
Нарушение устойчивости наступает по отношению к локальным отклонениям от равновесной концентрации. Если случайно возникшие неоднородности состава не рассасываются, а усиливаются реакцией системы, то это соответствует отрицательному коэффициенту диффузии $D$,восходящей“ диффузии.

Следовательно, „восходящая“ диффузия, если в системе возможно образование химического соединения, инициирует прежде всего химическое взаимодействие атомов, и спинодальное расслоение есть процесс мгновенного выделения из однородного жидкого раствора химических соединений различной природы в соответствии с характером взаимодействия компонентов по диаграмме состояния сплавов [11].

Таким образом, условие диффузионной устойчивости системы (рис. 2 и 3 ) имеет вид

$$
\frac{\partial \mu_{1}}{\partial x_{1}}>0
$$

Для неустойчивых лабильных состояний системы внутри купола расслоения (рис. 4 и 5), диффузионные процессы в системе („восходящая“ диффузия) определяются условием

$$
\frac{\partial \mu_{1}}{\partial x_{1}}<0
$$

Спинодаль $s$ как граница диффузионной устойчивости определяется условием

$$
\frac{\partial \mu_{1}}{\partial x_{1}}=0
$$

Рассмотрим процесс спинодального распада с использованием мольного термодинамического потенциала Гиббса $[10,11]$

$$
\varphi=x_{1} \mu_{1}+x_{2} \mu_{2}
$$

Представим выражение (7) через производные:

$$
\frac{\partial \varphi}{\partial x_{1}}=\mu_{1}-\mu_{2}, \quad \frac{\partial^{2} \varphi}{\partial x_{1}^{2}}=\frac{1}{x_{2}} \frac{\partial \mu_{1}}{\partial x_{1}} .
$$

На рис. 7 дана схематическая зависимость мольного потенциала $\varphi$ от концентрации для двух температур ниже и выше критической $T_{\mathrm{cr}}$ (рис. 6).

Нижняя кривая для условия метастабильного равновесия $T>T_{\text {cr }}$ (рис. 7) всюду выпуклая к оси составов. Это обеспечивает диффузионную устойчивость раствора во всем интервале концентраций $\left(\partial^{2} \varphi / \partial x_{1}^{2}>0\right)$, и одновременно делает невозможным разделение системы на сосуществующие фазы, т. е. спинодальное расслоение системы запрещено и ее затвердевание происходит по классическому механизму кристаллизации (рис. 2 и 3). В этом случае фазовое равновесие в системе соответствует минимальному уровню мольного термодинамического потенциала $\varphi(x)=\min$.

Верхняя кривая для условия спинодального расслоения $T<T_{\text {cr }}$ (рис. 7) имеет выпуклые и вогнутые участки. 


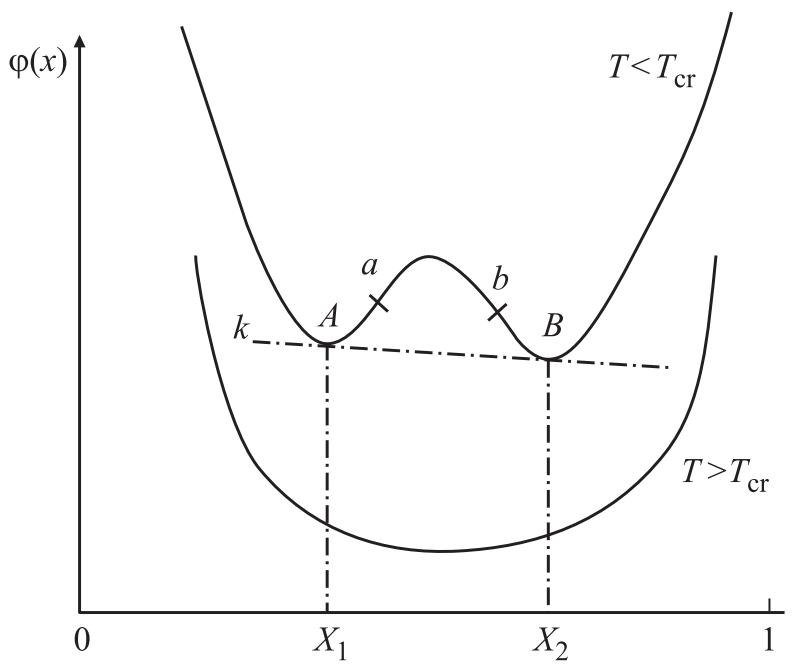

Рис. 7. Зависимость мольного термодинамического потенциала Гиббса от концентрации двухкомпонентного расслаивающегося раствора при температурах ниже и выше критической.

Точки перегиба $a, b$ принадлежат к границе устойчивости однородных состояний, для которых $\left(\partial^{2} \varphi / \partial x_{1}^{2}=0\right)$, а точки $A$ и $B$ соответствуют равновесно сосуществующим конденсированным фазам как продуктам распада раствора при спинодальном расслоении.

Конода $k$ как общая касательная к двум выпуклым участкам кривой в точках $A$ и $B$ показывает, что в этих точках мольный термодинамический потенциал $\varphi(x)=$ const и $\varphi(x)=\min$ при максимально предельной концентрации $X_{1}$ и $X_{2}$ соответственно в конденсированных фазах $A$ и $B$.

Для реализации спинодального распада необходимо по возможности быстро перевести систему из области 1 (рис. 7, точка $a$ ), в область 3 (рис. 7, точка $b$ ), например, закалкой из жидкого состояния, т.е. необходимо обеспечить значительное переохлаждение системы $\Delta T=T_{a}-T_{b}$. На рис. 5 показана микроструктура спинодального распада жидкой вольфрамсодержащей фазы.

В.С. Леонов в работе [12] рассчитал удельное энерговыделение на единицу массы частицы, которая составила $0.9 \cdot 10^{9} \mathrm{~J} / \mathrm{kg}$. Данный уровень энерговыделения на фронте движения частицы не только расплавляет металл, но и частично испаряет его и частица вольфрама фактически перемещается в канале из расплава. Эти явления способствуют активации взаимной диффузии $\mathrm{W}$, $\mathrm{C}$ и $\mathrm{Fe}$. Как следствие, происходит карбидизация частиц вольфрама (рис. 5, точка 1) в процессе движения и образование карбида вольфрама в соответствии с диаграммой $\mathrm{W}-\mathrm{C}$. Кроме этого, происходит и растворение частиц вольфрама в расплаве высокоуглеродистой стали У8. На рис. 5 частицы вольфрама имеют сглаженную, овальную поверхность, что говорит о растворении поверхностных слоев частицы, которая до растворения имеет ярко выраженную ограненную поверхность.
Таким образом, при своем движении в объеме стали У8 поверхность крупных частиц вольфрама обволакивается оболочкой насыщенного вольфрамом расплава. При остановке частицы фактически происходит мгновенная закалка расплава со значительным переохлаждением и его кристаллизация по механизму спинодального распада на фазу с низким содержанием вольфрама (аустенит, рис. 5 , точки 4 и 5$)$ и фазу с высоким содержанием вольфрама (сферические кристаллы карбида вольфрама, рис. 5, точки 2 и 3 ).

Э. Родунер показал на основе закона Веймарна [13], что чем выше степень исходного перенасыщения системы, тем большее число зародышей в ней образуется и тем меньше конечный размер формирующихся кристаллов. Причем в соответствии с законом Вульфа в данных условиях кристаллизация протекает по сферолитному механизму.

При спинодальном распаде в общем случае диффузионный поток определяется не градиентом концентрации, а градиентом химического потенциала. В этом случае диффузионные процессы ведут к состоянию, характеризуемому условием постоянства в данном объеме химического потенциала $\mu=$ const и расслоению системы на концентрационные зоны, в которых происходит кристаллизация конденсированных фаз $A$ и $B$ (рис. 7). Как следствие, система кристаллизуется в виде сферолитных кристаллов. Причем процесс кристаллизации начинается на фазовой поверхности раздела карбид WC-расплав, как на подложке, формируя карбидную „бахрому“ по поверхности раздела (рис. 5).

На рис. 4 структура сформирована в результате спинодального распада твердого раствора с формированием нитевидных кристаллов карбида вольфрама, чередующихся с изолированными глобулярными частицами карбида вольфрама высокой степени дисперсности. Причем сами нити состоят из коагулировавших мельчайших глобулей карбида вольфрама. Жидкофазные области в функциональной поверхности стали 45 не обнаружены, поскольку энергии электрического импульса не достаточно для перевода системы в жидкофазное состояние.

В работе [14] показано, что промежуточные распадные структуры, возникающие на этапе кинетической стабилизации спинодального превращения, являются квазистационарными и достаточно далеки от полного термодинамического равновесия. Как правило, на ранних стадиях спинодального расслоения формируется зернистая релаксационная структура без фазовых границ. На более поздних стадиях - одна из фаз диспергирована внутри другой при наличии устойчивой межфазной границы, что полностью соответствует характеру микроструктуры на рис. 4 и 5. Подобные структуры формируются периодически повторяющимися фрагментами и являются в общем случае метастабильными. Метастабильность указанных структур связана с торможением кинетики при синодальном распаде, при этом на этапе кинетической стабилизации свободная энергия системы практически 
неизменна (рис. 7). Таким образом, формирование структур на рис. 4 и 5 происходит по единому механизму спинодального распада соответственно твердого раствора и расплава.

Если охлаждение является достаточно медленным, то полный или частичный распад жидкости или твердого раствора на равновесные фазы может произойти по классическому механизму зародышеобразования уже в области метастабильных состояний 2 (рис. 6), что соответствует характеру структурообразования на рис. 2 и 3.

\section{Выводы}

1. Структурообразование в высокоэнергетических процессах имплантирования определяется условиями переохлаждения и протекает по двум механизмам классическому диффузионному механизму распада пересыщенных твердых растворов и спинодальному распаду как твердых растворов, так и жидкофазных зон.

2. Следствием реализации данных механизмов структурообразования является формирование градиентной структуры функциональной поверхности, характеризующейся кристаллизацией глобулярных и нитевидных карбидов вольфрама, композиционно упрочняющих ячеистую структуру стабилизированного аустенита.

3. При комбинированной импульсной электромеханической обработке при имплантировании карбида вольфрама температура в зоне контакта ролика и детали достигает уровня $1300^{\circ} \mathrm{C}$, что ведет к интенсивному растворению частичек карбида вольфрама, перенасыщению аустенита вольфрамом и к его последующему распаду на высокодисперсные структуры.

4. При использовании технологии эффекта сверхглубокого проникания частиц зафиксировано образование зон расплава вблизи частиц вольфрама, которые претерпевают одновременный процесс поверхностного растворения и карбидизации, с последующим процессом спинодального распада расплава стали У8 $\left(t_{\text {melt }}=1450^{\circ} \mathrm{C}\right)$, обогащенного вольфрамом и формированием высокодисперсной карбидо-аустенитной структуры, армированной глобулярными включениями карбида вольфрама.

Исследование выполнено при финансовой поддержке РФФИ в рамках научного проекта № 15-08-00571 а.

\section{Список литературы}

[1] Хейфеи, М.Л. // Наукоемкие технологии в машиностроении. 2016. № 4. С. 3-9.

[2] Григорьев С.Н., Тарасова Т.В. // МиТОМ. 2015. № 10. C. 5-10.

[3] Горленко А.О. // Вестник БГТУ. 2011. № 3. С. 4-8.

[4] Горленко А.О., Горленко О.А. // Наукоемкие технологии в машиностроении. 2011. № 6. С. 21-25.

[5] Давыдов С.В., Горленко А.О., Сканцев В.М., Куракин М.Ю. // МиТОМ. 2014. № 5 (707). С. 46-50.

[6] Ушеренко С.М. // ИФЖ. 2002. Т. 75. № 3. С. 183-198.
[7] Роман О.В., Андилевко С.К., Карпенко С.С., Романов Г.С., Шилкин В.А. // ИФЖ. 2002. Т. 75. № 4. С. 187-199.

[8] Кирсанов Р.Г., Петров Е.В., Кривченко А.Л. // Деформация и разрушение материалов. 2010. № 6. С. 43-46.

[9] Кирсанов Р.Г., Кривченко А.Л., Петров Е.В., Исаев Д.В. // ФХОМ. 2008. № 6. С. 46-50.

[10] Скрипов В.П., Скрипов А.В. // УФН. 1979. Т. 128. № 2. C. 193-231.

[11] Краско Г.Л., Любов Б.Я. // ФММ. 1961. Т. 11. Вып. 2. C. $186-193$.

[12] Леонов В.С. Холодный синтез в эффекте Ушеренко и его применение в энергетике. М.: Агроконсалт, 2001. 76 с.

[13] Родунер Э. Размерные эффекты в наноматериалах. М.: Техносфера, 2010. $352 \mathrm{c}$.

[14] Бункин Н.Ф., Лобеев А.В., Ляхов Г.А. // УФН. 1997. Т. 167. № 10. C. $1069-1085$. 